\title{
Delays in admitting aged persons to the mental health ward from the emergency department
}

Euan Donley ${ }^{1,2^{*}}$

*Correspondence: euan.donley@svha.org.au

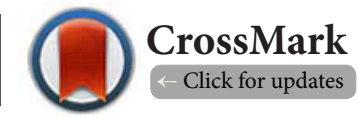

'Eastern Health Psychiatric and Emergency Response Team, Australia.

${ }^{2}$ St Vincent's Hospital Melbourne Social Work Department, Australia.

\begin{abstract}
Emergency Departments (EDs) continue to experience a rise in presentations and an even greater rise in mental health presentations. An older person in a mental health crisis presenting to the ED is more likely to experience comorbidities and a longer ED length of stay (ED-LOS). This results in poorer outcomes for the individual and the organisation. Many older persons in this scenario undergo comprehensive organic screening to exclude any organic cause for their presentation. This mixed methods analysis audited hospital files over a one-year period, examining the reasons for ED-LOS. A large proportion of the aged population required organic screening, resulting in longer ED-LOS, despite mental health bed availability. This study acknowledges that organic screening of any mental health person is of important value; however, notes that screening appears to be determined by age rather than clinical presentation and at times be better suited outside of the ED.
\end{abstract}

Keywords: Emergency, aged persons, mental health, crisis

\section{Background}

Emergency Departments (EDs) are on the front line for individuals presenting with a range of acute mental health crises requiring urgent assessment and support [1]. These types of presentations continue to increase by about $6.5 \%$ each year, more than triple the amount of ED physical health presentations [2], creating significant demand on resources. While a range of community mental health treatment options can be used to discharge and support individuals at home [3], many individuals presenting to the ED still require inpatient mental health admission [4].

Individuals requiring any type of admission to a hospital ward regularly experience an extended ED length of stay (ED-LOS) [5]. These lengthy times in the ED have a range of poor consequences for the individual and the organisation. For example, the individual is more likely to experience a negative impact on their health, more likely to require a subsequent hospital admission, and less likely to be satisfied with the ED experience [6]. For the organisation, extended ED-LOS can result in an access block to hospital services, overcrowding of the ED [7], and higher organisational costs [8].

For mental health patients in the ED, the average ED-LOS is even longer, due to the complexities of assessment and treatment [9]. In these cases, there are many reasons for extended ED-LOS across the age range. The adolescent population waiting for a mental health bed generally spend longer times in the ED [10]. This population may present due to an overdose or an episode of self-harm [11], may require further family or social support due to their younger age [12], and may require comprehensive mental health assessment. The adult mental health patient is also likely to have delays due to these reasons. However, the ED-LOS can also be attributed to the unavailability of an inpatient mental health bed [13].

An older person (aged 65 years and over) presenting to the $E D$ is more likely to experience a range of ongoing poor health and chronic conditions [14]. Any ED presentation for older persons is associated with functional decline for the individual and higher costs to the organisation [15]. An older person with a behavioural disturbance has a higher rate of comorbidities, cognitive impairment, and extended ED-LOS [16]. These comorbidities are a driving factor behind the ED arranging extensive organic screening (also known as medical clearance) of older persons in the ED experiencing a mental health crisis. The purpose of this is to exclude, or otherwise, an acute organic 
cause for the presenting symptomology $[17,18]$.

The concept of medical clearance comes with some controversy within the ED context. It is important to note that individuals with mental health disorders are more likely to have medical comorbidities that require assessment and follow up $[19,20]$. The ED is well placed to provide medical assessment for mental health patients and this population does require comprehensive physical examination [21]. However, it has also been argued that extensive organic testing in the ED rarely changes health management, as appropriate observations, history, and physical examination are usually all that is required [22]. This type of organic screening (searching for cause) is different to medical treatment required for a known presentation (such as an overdose).

Therefore, the aged person appears to be at a distinct disadvantage when presenting to the ED with a mental health related problem. Individuals of all ages waiting for mental health beds are associated with longer ED-LOS [23] and individuals who are older have a further disadvantage of greater ED-LOS, regardless of presenting factors $[\mathbf{1 8 , 2 4}]$. Thus, an older person with a behavioural disturbance in the ED automatically incurs this twofold disadvantage, resulting in exacerbated ED-LOS.

Eastern Health in Victoria, Australia is a metropolitan health network with three hospital EDs and a number of adolescent, adult, and older person's mental health wards. The network covers a large and diverse region that encompasses a range of socioeconomic, cultural, inner city, suburban, and rural regions, with many patients presenting to EDs with acute mental health crises.

The purpose of this study is to compare the Eastern Health hospital ED-LOS for older persons awaiting a mental health bed with other age ranges and explore the cause of the delays for each group.

\section{Methodology}

Several network electronic records were audited to review time codes and clinical documentation. The Client Management Interface (CMI) is an electronic record used by mental health services which documents all of the patients seen, including statistical data and clinical information. Symphony is an ED-based system that is used to collate arrival and departure times, when ED clinicians begin treatment, observations, and ordering of pathology or radiology requirements. Symphony is also used by clinicians for free text to document clinical notes. The Electronic Medical Record (EMR) works the same as Symphony, but is only used in one of the three EDs in the network. Finally, the Clinical Patient Folder (CPF) collates much of this information to summarise statistical data and store clinical notes and was used to confirm other electronic records were accurate.

Ethics was approved by the Eastern Health Office of Research and Ethics (ref: QA105:2018).

Results were collated via a mixed method analysis, which is a reliable methodology used when one method of analysis is insufficient [25]. In this case, quantitative data was used to examine trends in demographics such as; age, arrival time, assessment time, and departure times. A qualitative thematic analysis examined the ED clinician notes (free text). This thematic analysis was undertaken to analyse the nature of patient treatment in the ED and any reasons for a delay in mental health ward admission. For example, "chase bloods" (file number 13) or "awaiting CT results" (file number 6) denoted there was a medical reason for the delay. Other examples include "ambulance booked" (file 35), denoting a delay in transport, or "awaiting psych plan" (file number 52), denoting that the delay was due to a wait for the mental health assessment.

This mixed method analysis was conducted for a period of one year, from November $1^{\text {st }} 2017$ to November $1^{\text {st }} 2018$. The search was divided into three groups of patients in EDs awaiting mental health admission: adolescent (aged 13-17), adult (aged 18-64), and older persons (aged 65 and above). Individuals admitted to the medical ward or short stay ward from the ED were excluded, as it was not a direct ED to mental health ward transfer. All three EDs in the network were audited. At Angliss Hospital ED, 15 files were audited; at Box Hill Hospital ED, 15 files were audited; and at Maroondah Hospital ED, 30 files were audited, due to the significantly higher numbers of mental health assessments performed there.

\section{Results}

A CMI search from a one-year period for all of Eastern Health ED sites (Angliss, Maroondah and Box Hill) was undertaken from dates November $1^{\text {st }} 2017$ to November $1^{\text {st }} 2018$. According to the CMl, there were 303 adolescents admitted to the mental health adolescent unit, 1,392 adults admitted to the mental health ward, and 128 aged persons admitted to the aged persons mental health ward (see Figure 1).

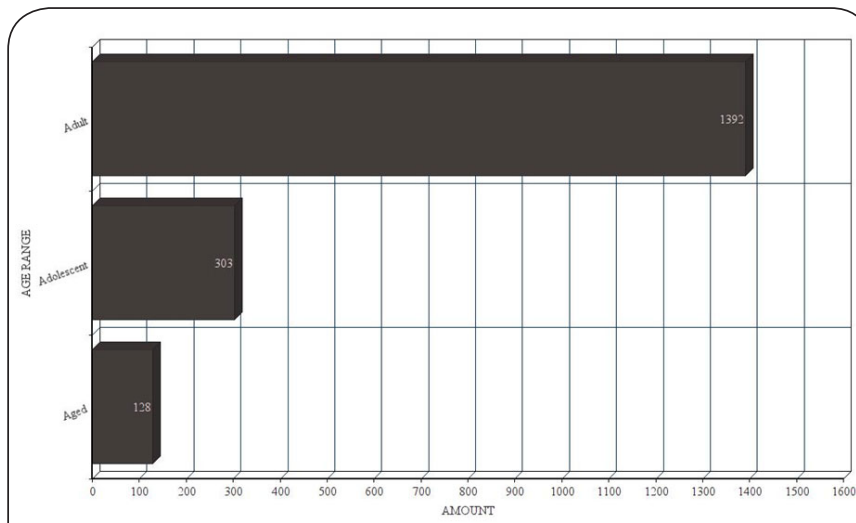

Figure 1. Mental health admissions via ED.

\section{Length of stay in EDs}

Over the one-year period, the average ED-LOS for adolescents admitted directly to the mental health ward was 344.9 minutes (5.7 hours), with a range of 100 minutes ( 1.7 hours) to 984 
minutes (16.4 hours). The average time to have the psychiatric assessment completed was 234.6 minutes (3.9 hours). The main reasons for extended ED-LOS included awaiting transport to the adolescent ward (35\%), waiting more than 4 hours for psychiatric assessment (25\%), and requiring medical treatment from overdose (10\%).

The average ED-LOS for adults admitted to the mental health ward from the ED was 684.37 minutes (11.4 hours), with a range of 195 minutes (3.3 hours) to 1296 minutes (21.6 hours). Overall, the average wait time for the psychiatric assessment to be completed was 292.3 minutes ( 4.9 hours). The main reason for extended ED-LOS was not having an available mental health bed (40\%), and for those waiting a mental health bed the ED-LOS averaging 1040.9 minutes (17.4 hours). With this group removed, the average wait time was 365.5 minutes (5.9 hours). Other reasons for extended LOS include waiting more than 4 hours for psychiatric assessment (15\%), further medical intervention required following overdose or self-harm (15\%), and alcohol intoxication (5\%).

The total average ED-LOS for older persons (aged 65+) requiring mental health admission was 456.15 minutes (7.6 hours). The longest wait from arrival to ED departure was 1034 minutes (17.2 hours), with the shortest wait being 147 minutes (2.45 hours). The average time from arrival to completion of psychiatric assessment was 253.95 mins (4.2 hours).

The main reason for an extended ED-LOS in older persons was awaiting medical clearance (organic screening rather than medical treatment of injury) prior to transfer (75\%). The average ED-LOS for older persons awaiting medical clearance was 539.8 minutes ( 9 hours).The average wait time from arrival to medical clearance $(\mathrm{N}=13)$ was 356.8 minutes ( 5.9 hours), while the time awaiting transport after being medically cleared $(\mathrm{N}=9)$ was 127.2 minutes (2.1 hours). Notably, there were no individuals in this group who had extended ED-LOS due to there not being an older person's mental health bed available. Other reasons for extended ED-LOS included awaiting transport (15\%), awaiting psychiatric assessment (5\%), and overdose (5\%) -see Figure 2.

In summary, and assuming there are current mental health beds available, the adolescent population average ED-LOS is 5.7 hours, the adult population average ED-LOS is 5.9 hours, and the older population average ED-LOS is 7.6 hours.

\section{Discussion}

It is well established that lengthy times in EDs result in poorer outcomes for the patient and the organisation, as well as poor patient flow, which affects individuals waiting for ED treatment to commence [26].

For mental health patients, the assessment of physical health is an important part of comprehensive healthcare and for the exclusion of any organic cause for the ED presentation. However, on many occasions, the ED organic tests that are required prior to mental health ward transfer appear to be influenced by age (65) rather than clinical presentation.

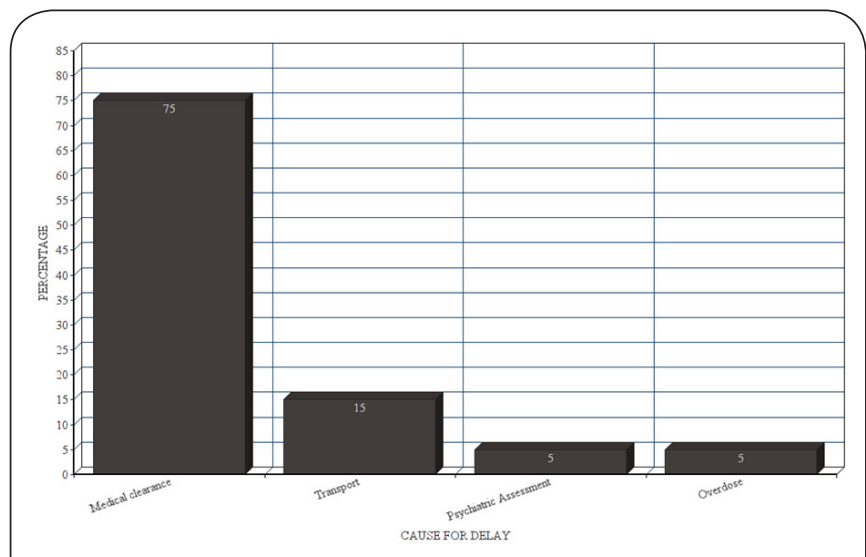

Figure 2. Breakdown of ED-LOS older mental health patients.

Older persons' mental health wards may, rightly, argue that they are not well positioned to treat individuals with significant physical comorbidities. Therefore, further research and discussion is required on how appropriate organic screening for older persons should be conducted and if the ED is the most suitable environment for this to occur. Further consideration should also be given to how any ED organic screening is likely to change the management of the older person in the $E D$, and if the aged mental health ward requires any further resources to assess or treat any organic needs for the older mental health patient.

\section{Limitations}

Eastern Health is a public funded health network and has general reliability, but cannot be indicative of worldwide rural systems. While the findings are based on rigorous data analysis, at times the ED clinical documentation (free text) was lacking, which is a limitation of this design.

\section{Conclusion}

Emergency Departments are getting busier and the rate of mental health presentations are increasing at a greater rate than other reasons for presentation. Mental health patients require comprehensive assessments and are in EDs longer than other populations. An older person presenting to the ED with a mental health problem is more likely to experience comorbidities and an even longer ED-LOS. This study has highlighted that the majority of extended ED-LOS for older ED patients were due to organic screening that showed no acute organic cause for the ED presentation. A long ED-LOS is more likely to result in poor outcomes for the individual and the organisation. Further consideration is required as to what organic tests are required and clinically indicated, if these tests are likely to change management, and if these can only be performed in the ED. Further consideration should also be given to any resources the aged persons' mental health ward requires. 
Euan Donley, Emergency Medicine \& Health Care 2019,

Competing interests

The author declares that he has no competing interests.

Publication history

EIC: Joseph Varon, University of Texas, USA.

Received: 03-Mar-2019 Final Revised: 13-Apr-2019

Accepted: 16-Apr-2019 Published: 02-May-2019

\section{References}

1. Barratt H, Rojas-Garcia A, Clarke K, Moore A, Whittington C, Stockton $S$, Thomas J, Pilling $S$ and Raine R. Epidemiology of Mental Health Attendances at Emergency Departments: Systematic Review and MetaAnalysis. PLoS One. 2016; 11:e0154449. | Article | PubMed Abstract | PubMed FullText

2. Hiscock H, Neely RJ, Lei S and Freed G. Paediatric mental and physical health presentations to emergency departments, Victoria, 2008-15. Med J Aust. 2018; 208:343-348. | Article I PubMed

3. Stanley, Barbara and Gregory K. Brown. Safety planning intervention: a brief intervention to mitigate suicide risk. Cognitive and Behavioral Practice. 2012; 19:256-264.

4. Smith MW, Stocks $C$ and Santora PB. Hospital readmission rates and emergency department visits for mental health and substance abuse conditions. Community Ment Health J. 2015; 51:190-7. | Article | PubMed

5. H. Song, A. L. Tucker and K. L. Murrell. The diseconomies of queue pooling: An empirical investigation of emergency department length of stay. Management Science. 2015; 61:3032-3053.

6. Vermeulen MJ, Guttmann A, Stukel TA, Kachra A, Sivilotti ML, Rowe BH, Dreyer J, Bell R and Schull M. Are reductions in emergency department length of stay associated with improvements in quality of care? A difference-in-differences analysis. BMJ Qual Saf. 2016; 25:489-98. | Article | PubMed Abstract | PubMed FullText

7. Chang G, Weiss AP, Orav EJ, Jones JA, Finn CT, Gitlin DF, Haimovici F, Hazen E, Kosowsky JM, Schechter MD and Rauch SL. Hospital variability in emergency department length of stay for adult patients receiving psychiatric consultation: a prospective study. Ann Emerg Med. 2011; 58:127-136. | Article | PubMed

8. Cullen L, Greenslade J, Merollini K, Graves N, Hammett CJ, Hawkins T, Than MP, Brown AF, Huang CB, Panahi SE, Dalton E and Parsonage WA. Cost and outcomes of assessing patients with chest pain in an Australian emergency department. Med J Aust. 2015; 202:427-32. Article I PubMed

9. Nicks BA and Manthey DM. The impact of psychiatric patient boarding in emergency departments. Emerg Med Int. 2012; 2012:360308. | Article | PubMed Abstract | PubMed FullText

10. S. D. Case, B. G. Case, M. Olfson, J. G. Linakis and E. M. Laska. Length of stay of paediatric mental health emergency department visits in the United States. Journal of the American Academy of Child \& Adolescent Psychiatry. 2011; 50:1110-1119.

11. Mapelli E, Black T and Doan Q. Trends in Pediatric Emergency Department Utilization for Mental Health-Related Visits. J Pediatr. 2015; 167:905-10. | Article | PubMed

12. Kuhlthau KA, Bloom S, Van Cleave J, Knapp AA, Romm D, Klatka K, Homer $\mathrm{CJ}$, Newacheck PW and Perrin JM. Evidence for family-centered care for children with special health care needs: a systematic review. Acad Pediatr. 2011; 11:136-43. | Article | PubMed

13. Weiss AP, Chang G, Rauch SL, Smallwood JA, Schechter M, Kosowsky J, Hazen E, Haimovici F, Gitlin DF, Finn CT and Orav EJ. Patient- and practice-related determinants of emergency department length of stay for patients with psychiatric illness. Ann Emerg Med. 2012; 60:162-71 e5. | Article | PubMed

14. Collard RM, Boter H, Schoevers RA and Oude Voshaar RC. Prevalence of frailty in community-dwelling older persons: a systematic review. J Am Geriatr Soc. 2012; 60:1487-92. | Article | PubMed

15. Nagurney JM, Fleischman W, Han L, Leo-Summers L, Allore HG and Gill TM. Emergency Department Visits Without Hospitalization Are
Associated With Functional Decline in Older Persons. Ann Emerg Med. 2017; 69:426-433. | Article | PubMed Abstract | PubMed FullText

16. Rhodes SM, Patanwala AE, Cremer JK, Marshburn ES, Herman M, Shirazi FM, Harrison-Monroe P, Wendel C, Fain M, Mohler J and Sanders AB. Predictors of Prolonged Length of Stay and Adverse Events among Older Adults with Behavioral Health-Related Emergency Department Visits: A Systematic Medical Record Review. J Emerg Med. 2016; 50:14352. I Article I PubMed

17. Ellis G, Marshall T and Ritchie C. Comprehensive geriatric assessment in the emergency department. Clin Interv Aging. 2014; 9:2033-43. | Article | PubMed Abstract | PubMed FullText

18. Latham LP and Ackroyd-Stolarz S. Emergency department utilization by older adults: a descriptive study. Can Geriatr J. 2014; 17:118-25. | Article | PubMed Abstract | PubMed FullText

19. Naylor, Chris, Michael Parsonage, David McDaid, Martin Knapp, Matt Fossey and Amy Galea. Long-term conditions and mental health: the cost of co-morbidities. 2012.

20. Bartels SJ. Caring for the whole person: integrated health care for older adults with severe mental illness and medical comorbidity. J Am Geriatr Soc. 2004; 52:S249-57. | Article | PubMed

21. Szpakowicz M and Herd A. "Medically cleared": how well are patients with psychiatric presentations examined by emergency physicians? J Emerg Med. 2008; 35:369-72. | Article | PubMed

22. Janiak BD and Atteberry S. Medical clearance of the psychiatric patient in the emergency department. J Emerg Med. 2012; 43:866-70. | Article | PubMed

23. Pearlmutter MD, Dwyer KH, Burke LG, Rathlev N, Maranda L and Volturo G. Analysis of Emergency Department Length of Stay for Mental Health Patients at Ten Massachusetts Emergency Departments. Ann Emerg Med. 2017; 70:193-202 e16. I Article | PubMed

24. Casalino E, Wargon M, Peroziello A, Choquet C, Leroy C, Beaune S, Pereira L, Bernard J and Buzzi JC. Predictive factors for longer length of stay in an emergency department: a prospective multicentre study evaluating the impact of age, patient's clinical acuity and complexity, and care pathways. Emerg Med J. 2014; 31:361-8. | Article I PubMed

25. Palinkas LA, Horwitz SM, Green CA, Wisdom JP, Duan N and Hoagwood K. Purposeful Sampling for Qualitative Data Collection and Analysis in Mixed Method Implementation Research. Adm Policy Ment Health. 2015; 42:533-44. | Article | PubMed Abstract | PubMed FullText

26. Brouns SH, Stassen PM, Lambooij SL, Dieleman J, Vanderfeesten IT and Haak HR. Organisational Factors Induce Prolonged Emergency Department Length of Stay in Elderly Patients--A Retrospective Cohort Study. PLoS One. 2015; 10:e0135066. | Article I PubMed Abstract | PubMed FullText

\section{Citation:}

Donley E. Delays in admitting aged persons to the mental health ward from the emergency department. Emerg Med Health Care. 2019; 6:1. http://dx.doi.org/10.7243/2052-6229-6-1 